\title{
Food Safety: Pathogen Transmission Routes, Hygiene Practices and Prevention
}

Improvements in food safety require initiatives that address risks identified along the 'farm-to-fork continuum'. Two papers in this issue of the Journal look at opposite ends of this continuum; an article by Akoachere et al. examines a common foodborne pathogen (Salmonella Typhimurium) in livestock (1) and Takanashi et al. assess the impact of food hygiene in the home on diarrhoea (2).

Foodborne disease is defined as illness resulting from consumption of contaminated food; food can be contaminated with microbial pathogens or a toxic substance (3). Many common foodborne pathogens are zoonotic (4). To attribute diarrhoeal disease to zoonotic transmission or other transmission routes, data collected for specific pathogens through investigations of outbreaks, analytical studies, and laboratory-based studies can provide insights. Transmission from animals to humans can occur through direct contact (5), consumption or handling of meat (6), consumption of unpasteurized milk $(7)$, untreated water $(8,9)$ or consumption of contaminated fresh produce (10).

In the article by Akoachere et al., microbial subtyping was used as a means to link Salmonella Typhimurium-related disease in humans with animal reservoirs (1). In investigations of outbreaks, the linkage between humans and animals is clear as there is laboratory evidence, along with information for a specific exposure window $(11,12)$. In analytical studies, epidemiological evidence suggests a link by detecting an elevated risk of being an $S$. Typhimurium case among those exposed to meats (13) or animal contact (14). These data, however, lack accompanying microbiological evidence. In the article by Akoachere et al. (1), microbiological

Correspondence and reprint requests should be addressed to:

Dr. Leanne E. Unicomb

Head, Water and Sanitation Cluster

Programme on Infectious Diseases and Vaccine

Sciences

Health Systems and Infectious Diseases Division

ICDDR,B

GPO Box 128, Dhaka 1000

Bangladesh

Email: leanne@icddrb.org

Fax: +880-2-8811568 evidence is proposed, in the absence of an epidemiological link. There are limitations to this approach to attributing food-animal exposure to human disease and so the findings should be interpreted with caution. The authors conclude that their findings are circumstantial. Using microbial subtyping data to attribute human disease to a source can be useful for prioritizing intervention strategies. Recent advances in the use of Salmonella subtyping data to attribute human infections to animal reservoirs have been described (15). This may be further assisted by the wider use of multiple-locus variablenumber tandem repeat analysis (MLVA) developed for several Salmonella serovars (16-18). The method has the advantages of being rapid, cheap, and reproducible, offering advantages over traditional Salmonella serotyping and phage typing. MLVA has initially been used in outbreak situations and is now being applied as a routine method in some settings (19).

The study described by Akoachere et al. also reports antimicrobial resistance of the $S$. Typhimurium isolates (1). There has been considerable debate on antimicrobial resistance among foodborne pathogens and the role of clinical usage versus antimicrobial use during food-animal rearing. The source of resistance remains controversial and has been the subject of many analytical studies that include human and/ or animal isolates and data on antimicrobial agent consumption for humans and animals (20-23).

In addition to identifying areas for improvement at the food production and food processing level, collecting evidence of food safety at the point of consumption is warranted. Epidemiological data suggest that poor food-hygiene practices are responsible for a substantial proportion of foodborne disease (24).

In this issue, an article by Takanashi et al. examines the role of food-hygiene practices on diarrhoeal disease among children (2). They found limited association between food-hygiene or general hygiene behaviours and diarrhoea. This is consistent with the findings from a systematic review of the effect of domestic kitchen-hygiene practices on diarrhoeal disease in developed countries (25). There is, however, evidence of a role of poor hygiene 
practices in diarrhoeal disease from investigation of outbreaks and environmental studies $(26,27)$. Collecting accurate information on hygiene practices is challenging. Self-reported food-handling and hygiene practices at home are unreliable compared to observed behaviours (24); this was acknowledged by the authors. For example, they found no association between diarrhoea and handwashing practices, a finding at odds with studies that have demonstrated the effectiveness of handwashing interventions on diarrhoea (28). The study reported in this issue focused on practices important for foodborne transmission, which include handwashing; this can have an impact on person-to-person transmission. Among the age-group of study children, diarrhoea may be due to pathogens acquired by the person-to-person and fomite transmission routes, in addition to the foodborne transmission route.

From a disease-prevention perspective, hygiene efforts at both farm and fork-end of the continuum are worth pursuing. Strong evidence of the impact of these initiatives will be required to satisfy the food industry and policy-makers that changes are needed. In addition to addressing animal and human hygiene, continued research to attribute disease to pathways and vehicles to target those of the greatest impact and/or with viable practical solutions is required.

\section{REFERENCES}

1. Akoachere J-FTK, Tanih NF, Ndip LM, Ndip RN. Phenotypic characterization of Salmonella Typhiumurium isolates from food-animals and abattoir drains in Buea, Cameroon. J Health Popul Nutr 2009;27:612-18.

2. Takanashi K, Chonan Y, Quyen DT, Khan NC, Poudel KC, Jimba M. Survey of food-hygiene practices at home and childhood diarrhoea in Hanoi, Viet Nam. J Health Popul Nutr 2009;27:602-11.

3. Foodborne disease. In: Wikipedia. (http://www.wikipedia.org, accessed on 29 August 2009).

4. Tauxe RV. Emerging foodborne pathogens. Int J Food Microbiol 2002;78:31-41.

5. Stirling J, Griffith M, Dooley JS, Goldsmith CE, Loughrey A, Lowery CJ et al. Zoonoses associated with petting farms and open zoos. Vector Borne Zoonotic Dis 2008;8:85-92.

6. McPherson M, Lalor K, Combs B, Raupach J, Stafford R, Kirk MD. Serogroup-specific risk factors for Shiga toxin-producing Escherichia coli infection in Australia. Clin Infect Dis 2009;49:249-56.

7. Oliver SP, Jayarao BM, Almeida RA. Foodborne patho- gens in milk and the dairy farm environment: food safety and public health implications. Foodborne Pathog Dis 2005;2:115-29.

8. Ashbolt RA, Kirk MD. Salmonella Mississippi infections in Tasmania: the role of native Australian animals and untreated drinking water. Epidemiol Infect 2006;134:1257-65.

9. Sutherland SJ, Gray JT, Menzies PI, Hook SE, Millman ST. Transmission of foodborne zoonotic pathogens to riparian areas by grazing sheep. Can J Vet Res 2009;73:125-31.

10. Lynch MF, Tauxe RV, Hedberg CW. The growing burden of foodborne outbreaks due to contaminated fresh produce: risks and opportunities. Epidemiol Infect 2009; 137:307-15.

11. Smith KE, Medus C, Meyer SD, Boxrud DJ, Leano F, Hedberg CW et al. Outbreaks of salmonellosis in Minnesota (1998 through 2006) associated with frozen, microwaveable, breaded, stuffed chicken products. $J$ Food Prot 2008;71:2153-60.

12. Kivi M, Hofhuis A, Notermans DW, Wannet WJ, Heck ME, Van De Giessen AW et al. A beef-associated outbreak of Salmonella Typhimurium DT104 in the Netherlands with implications for national and international policy. Epidemiol Infect 2007;135:890-9.

13. Delarocque-Astagneau E, Bouillant C, Vaillant V, Bouvet P, Grimont PA, Desenclos JC. Risk factors for the occurrence of sporadic Salmonella enterica serotype typhimurium infections in children in France: a national case-control study. Clin Infect Dis 2000;31:488-92.

14. Doré K, Buxton J, Henry B, Pollari F, Middleton D, Fyfe M et al.; Multi-Provincial Salmonella Typhimurium Case-Control Study Steering Committee. Risk factors for Salmonella Typhimurium DT104 and nonDT104 infection: a Canadian multi-provincial casecontrol study. Epidemiol Infect 2004;132:485-93.

15. Hald T, Vose D, Wegener HC, Koupeev T. A Bayesian approach to quantify the contribution of animal-food sources to human salmonellosis. Risk Anal 2004;24:255-69.

16. Davis MA, Baker KN, Call DR, Warnick LD, Soyer Y, Wiedmann $\mathrm{M}$ et al. Multilocus variable-number tandem-repeat method for typing Salmonella enterica serovar Newport. J Clin Microbiol 2009;47:1934-8.

17. Torpdahl M, Sørensen G, Lindstedt BA, Nielsen EM. Tandem repeat analysis for surveillance of human Salmonella Typhimurium infections. Emerg Infect Dis 2007;13:388-95.

18. Ross IL, Heuzenroeder MW. A comparison of two PCR-based typing methods with pulsed-field gel electrophoresis in Salmonella enterica serovar Enteritidis. Int J Med Microbiol 2009;299:410-20. 
19. Gilbert GL. Using MLVA to type strains of Salmonella Typhimurium in New South Wales. N SW Public Health Bull 2008;19:29-31.

20. Aarestrup FM, Wegener HC, Collignon P. Resistance in bacteria of the food chain: epidemiology and control strategies. Expert Rev Anti Infect Ther 2008;6:733-50.

21. Wassenaar TM, Silley P. Antimicrobial resistance in zoonotic bacteria: lessons learned from host-specific pathogens. Anim Health Res Rev 2008;9:177-86.

22. Nelson JM, Chiller TM, Powers JH, Angulo FJ. Fluoroquinolone-resistant Campylobacter species and the withdrawal of fluoroquinolones from use in poultry: a public health success story. Clin Infect Dis 2007;44:977-80.

23. Cox LA, Jr. Enrofloxacin in poultry and human health. Emerg Infect Dis 2006;12:872-3.

24. Redmond EC, Griffith CJ. Consumer food handling in the home: a review of food safety studies. J Food Prot 2003;66:130-61.

25. Stenberg A, Macdonald C, Hunter PR. How effective is good domestic kitchen hygiene at reducing diar- rhoeal disease in developed countries? A systematic review and reanalysis of the UK IID study. BMC Public Health 2008;8:71.

26. Olsen SJ, Hansen GR, Bartlett L, Fitzgerald C, Sonder A, Manjrekar R et al. An outbreak of Campylobacter jejuni infection associated with food handler contamination; the use of pulsed-field gel electrophoresis. $J$ Infect Dis 2001;183:164-7.

27. Butz AM, Fosarelli P, Dick J, Cusack T, Yolken R. Prevalence of rotavirus on high-risk fomites in day-care facilities. Pediatrics 1993;92:202-5.

28. Curtis V, Cairncross S. Effect of washing hands with soap on diarrhea risk in the community: a systematic review. Lancet Infect Dis 2003;3:275-81.

\section{Leanne E. Unicomb}

Head, Water and Sanitation Cluster

Programme on Infectious Diseases and Vaccine

Sciences

Health Systems and Infectious Diseases Division

ICDDR,B

GPO Box 128, Dhaka 1000

Bangladesh 